\title{
ChemComm
}

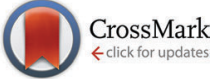

Cite this: Chem. Commun., 2015, 51, 3173

Received 13th December 2014 Accepted 2nd January 2015

DOI: $10.1039 / c 4 c c 09955 a$

www.rsc.org/chemcomm

\section{Solvent induced single-crystal to single-crystal structural transformation and concomitant transmetalation in a 3D cationic Zn(II)-framework $\dagger$}

\author{
Susan Sen, ${ }^{a}$ Subhadip Neogi, ${ }^{a}$ Kari Rissanen ${ }^{b}$ and Parimal K. Bharadwaj ${ }^{{ }^{a}}$
}

\begin{abstract}
A 3D cationic $\mathrm{Zn}(\mathrm{II})$ framework, based on $\mathrm{Zn}_{2}\left(\mathrm{CO}_{2}\right)_{4}$ paddle-wheel secondary building units (SBUs) and $\mathrm{Zn}_{16}\left(\mathrm{CO}_{2}\right)_{32}$ polyhedral supramolecular building blocks (SBBs), has been synthesized. At room temperature, the framework undergoes guest solvent triggered reversible structural transformation and concomitant $\mathrm{Zn}(\mathrm{II})$ to $\mathrm{Cu}($ II) transmetalation in a single-crystal to single-crystal fashion.
\end{abstract}

Most of the studies on metal-organic frameworks (MOFs) are concentrated towards the creation of robust frameworks, where particular emphasis has been focused on their ability to retain the architecture even after the removal of guest solvent molecules for practical applications. ${ }^{1}$ In addition to their large well-defined pore shapes and sizes, an important feature of these frameworks is the presence of metal clusters, serving as secondary building units (SBUs). ${ }^{2}$ Adopting the SBU approach, a large number of novel $\mathrm{MOFs}^{3-5}$ have been constructed. MOFs that undergo single-crystal to single-crystal (SC-SC) structural transformation ${ }^{6}$ triggered by external stimuli have received considerable attention recently. Selective molecular motions ${ }^{7}$ as well as metal/ligand substitution ${ }^{8}$ in MOF crystals without losing single crystallinity are largely being pursued in several laboratories to design and construct functional materials. ${ }^{9}$ Although substitution of a linker in a MOF by another has often been realized in SC-SC transformation, ${ }^{10}$ exchange of the metal, ${ }^{11}$ however, is experienced only in a handful of examples.

Transmetalation reactions are primarily attractive to overcome the limitation of achieving multifunctional MOFs by direct solvothermal synthesis ${ }^{12}$ and to fabricate the interior as well as exterior of MOF materials with improved properties. ${ }^{13}$ To better

\footnotetext{
${ }^{a}$ Department of Chemistry, Indian Institute of Technology, Kanpur 208016, India. E-mail: pkb@iitk.ac.in; Fax: (+91) 512-259-7436; Tel: (+91) 512-259-7034

${ }^{b}$ Department of Chemistry, NanoScience Center, University of Jyväskylä, P.O. Box 35, 40014 Jyväskylä, Finland. E-mail: kari.t.rissanen@jyu.fi $\dagger$ Electronic supplementary information (ESI) available: Experimental details, NMR, PXRD patterns, FT-IR spectra, TGA, SEM images, EDS spectrum, tables, additional figures and CIF files. CCDC 1037351 (1), 1037352 (2-MeCN), 1037353 (2-DCM), $1037354\left(\mathbf{1}_{\mathrm{Cu}}\right.$-DMF) and $1037355\left(\mathbf{2}_{\mathrm{Cu}}\right.$-MeCN). For ESI and crystallographic data in CIF or other electronic format see DOI: 10.1039/c4cc09955a
}

elucidate the exchange mechanism, investigation of the metal replacement behaviour is indispensable. Using a rigid and angular tetracarboxylic acid ligand $\left(\mathbf{H}_{\mathbf{4}} \mathbf{L}^{+}\right),{ }^{14}$ incorporating an imidazolium group in the middle and aromatic carboxylate at the terminals, a cationic $\mathrm{Zn}$ (II) framework (1) based on $\mathrm{Zn}_{2}\left(\mathrm{CO}_{2}\right)_{4}$ paddle-wheel SBUs and $\mathrm{Zn}_{16}\left(\mathrm{CO}_{2}\right)_{32}$ polyhedral supramolecular building blocks (SBBs) has been synthesized. We demonstrate that the imidazolium moiety reorients in solvents like acetonitrile, chloroform, dichloromethane, benzene, and toluene to make the dihedral angle between the plane of the imidazolium moiety and the phenyl ring to be $122.56^{\circ}$ in the transformed $\mathrm{Zn}$ (II) framework (2) while in solvents like dimethyl sulfoxide (DMSO), dimethylformamide (DMF), methanol ( $\mathrm{MeOH})$, tetrahydrofuran (THF), and dimethylcarbonate $\left(\mathrm{Me}_{2} \mathrm{CO}_{3}\right)$ the dihedral angle changes to $63.94^{\circ}$ in framework 1. Interestingly, the $\mathrm{Zn}$ (II)-MOF (1) readily undergoes transmetalation from $\mathrm{Zn}$ (II) to $\mathrm{Cu}$ (II), whereupon $\mathbf{1}$ is converted to $\mathbf{2}_{\mathbf{C u}}$, only when the dihedral angle changes from $63.94^{\circ}$ to $122.56^{\circ}$. To the best of our knowledge, this is the first report in which transmetalation has been achieved as a consequence of the change in the ligand conformation. In addition, the Cu-exchanged MOF $\mathbf{2}_{\mathbf{C u}}$ transforms into $\mathbf{1}_{\mathbf{C u}}$ in a reversible SC-SC fashion when simply dipped in solvents having at least one oxygen atom as a part of their molecule such as DMSO, $\mathrm{DMF}, \mathrm{MeOH}, \mathrm{THF}$, and dioxane. All the changes are realized in a SC-SC fashion at room temperature and characterized by single crystal X-ray diffraction studies.

Colorless octagonal crystals of $\left\{\left[\mathrm{Zn}_{2}(\mathbf{L})\left(\mathrm{H}_{2} \mathrm{O}\right)_{2}\right] \cdot \mathrm{NO}_{3} \cdot x \mathrm{DMF} \cdot y \mathrm{H}_{2} \mathrm{O}\right\}_{n}$ (1) were synthesized solvothermally by reacting 1,3-bis-(3,5dicarboxyphenyl) imidazoliumchloride $\left(\mathbf{L C l}^{-}=\mathbf{H}_{\mathbf{4}} \mathbf{L}^{+} \mathbf{C l}^{-}\right.$,) with $\mathrm{Zn}\left(\mathrm{NO}_{3}\right)_{2} \cdot 6 \mathrm{H}_{2} \mathrm{O}$ in DMF at $90{ }^{\circ} \mathrm{C}$ for 3 days. The single-crystal $\mathrm{X}$-ray diffraction study demonstrates (Table S1, ESI $\dagger$ ) that 1 crystallizes in the tetragonal $P 4_{2} / \mathrm{nnm}$ space group. Structural investigation revealed that the asymmetric unit contains one half of ligand L, two crystallographically independent Zn(II) ions (Zn1 and Zn2) each with half occupancy and one water molecule. Both Zn1 and $\mathrm{Zn} 2$ lie on the $C_{4}$ axis and adopt the square pyramidal geometry to coordinate with four $\mu_{2}-\eta^{1}, \eta^{1}$ carboxylates of $\mathbf{L}$ to form the paddle-wheel $\left[\mathrm{M}_{2}\left(\mathrm{CO}_{2}\right)_{4}\right]$, with an average $\mathrm{Zn}-\mathrm{Zn}$ distance of $3.009 \AA$

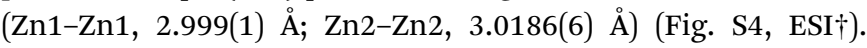




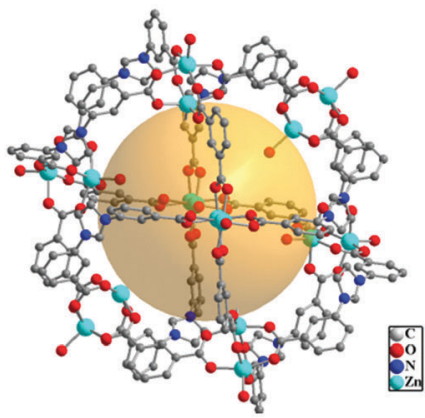

a)

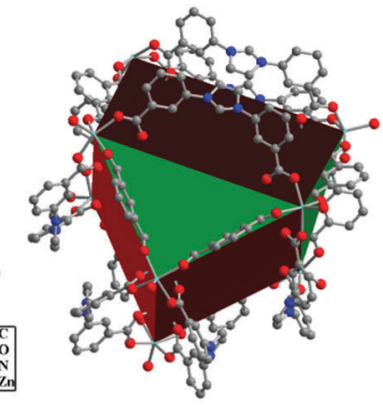

b)
Fig. 1 Representation of the (a) MOP and (b) gyrobifastigium.

The fifth coordination site is occupied by a solvent water molecule. Notably, the paddle-wheel $\mathrm{Zn}_{2}\left(\mathrm{CO}_{2}\right)_{4}$ carries no charge that enables the entire framework to be cationic, owing to the positive charge on the central imidazolium ring. ${ }^{14}$ The nitrate anion rests in the cavity. Although we could not locate this nitrate anion, due to the inherent disorder nature, its presence is confirmed by IR spectra (Fig. S8a, ESI $\dagger$ ). As illustrated in Fig. 1, eight $\mathbf{L}$ ligands are linked with eight $\mathrm{Zn}$ (II)-paddle-wheels to produce a $\mathrm{Zn}_{16}\left(\mathrm{CO}_{2}\right)_{32}$ gyrobifastigium polyhedra (a combination of two triangular prisms), having eight vertices, eight faces and fourteen edges, in which the core cavity is accessible through four triangular and four square faces.

The internal spherical cavity of this polyhedron in $\mathbf{1}$ has a diameter of $\sim 14.7 \AA$ (diameter refers to the atom-to-atom distance throughout this communication) ignoring coordinated solvents, while the size of the triangular aperture is $\sim 12.2 \AA$. All edges of the polyhedron are decorated with cationic imidazolium moieties that point outwards. These polyhedral $\mathrm{Zn}_{16}\left(\mathrm{CO}_{2}\right)_{32}$ units can be regarded as SBBs that are interconnected through the paddlewheel $\mathrm{Zn}_{2}\left(\mathrm{CO}_{2}\right)_{4}$ SBUs and $\mathbf{L}$ ligands to form a non-interpenetrated 3D structure. When viewed along the crystallographic $c$ axis, the structure presents 1D hexagonal channels, with a cross-section of $8.786 \AA$ A between the opposite vertices (Fig. S22, ESI $\dagger$ ). Views along $a$ and $b$ axes reveal additional square-shaped channels with a cross section of $8.839 \AA$ and $8.359 \AA$ (Fig. S23, ESI $\dagger$ ) respectively. These voids are occupied by solvent molecules and nitrate anions. The high disorder nature of the guest solvent molecules did not allow us to establish the guest molecules unambiguously. The total solvent-accessible volume is estimated using PLATON, ${ }^{15}$ which reveals the calculated guest accessible area per unit cell volume for 1 to be $5678 \AA^{3}(\sim 64 \%)$. Thermogravimetric analysis of 1 exhibits (Fig. S8b, ESI $\dagger$ ) a continuous loss of solvent molecules, starting from room temperature without a plateau, corroborating the limited thermal stability of the framework. The bulk-phase purity of $\mathbf{1}$ was confirmed by comparing the experimentally observed powder X-ray diffraction (PXRD) pattern with the simulated pattern (Fig. S24, ESI $\dagger$ ).

A close look into the packing diagram of 1 reveals that the water molecules coordinated to the $\mathrm{Zn}$ (II) ions of SBUs are projected towards the hexagonal channels and are also directed along the $a$ - and $b$-axes (Fig. S23, ESI $\dagger$ ). This observation led us to probe for possible substitution of the axial sites by other solvent molecules. Interestingly, when a single crystal of $\mathbf{1}$ is dipped into a solution of $\mathrm{CH}_{3} \mathrm{CN}$ for $24 \mathrm{~h}$ at room temperature, the colour and morphology of the crystal remain the same (Fig. S28, ESI $\dagger$ ); the structure reveals the formation of $\left\{\left[\mathrm{Zn}_{2}(\mathbf{L})\left(\mathrm{H}_{2} \mathrm{O}\right)_{2}\right] \cdot \mathrm{NO}_{3} \cdot y \mathrm{H}_{2} \mathrm{O} \cdot z \mathrm{MeCN}\right\}_{n}$ (2-MeCN), where the space group changes to $\mathrm{I}_{1} /$ amd, with considerable changes in the lattice parameters (Table S1, ESI $\dagger$ ). Single-crystal $\mathrm{X}$-ray analyses indicate the presence of three crystallographically independent $\mathrm{Zn}$ (II) ions and one entire ligand in the asymmetric unit. A comparison between the structures of 1 and 2-MeCN shows that the coordination modes of $\mathbf{L}$ ligands as well as the metal bound water molecules remain intact with the difference that the paddlewheel SBUs are twisted with respect to the isophthalate moiety, as a consequence of the free rotation of the imidazolium ring around the $\mathrm{C}-\mathrm{N}$ bond (Fig. 2a). This twist also affects many of the key dihedral angles, particularly the dihedral angle between the plane of the imidazolium moiety and the plane of the phenyl ring that changes from $63.94^{\circ}$ to $122.56^{\circ}$. Furthermore, the average $\mathrm{Zn}-\mathrm{Zn}$ distance in the $\mathrm{Zn}_{2}\left(\mathrm{CO}_{2}\right)_{4}$ paddle wheel units changes from $\sim 3.009 \AA$ in 1 to $~ 3.0190 \AA$ in 2 -MeCN (Zn1-Zn1, 3.0266(18) $\AA$; Zn2-Zn3, 3.0114(16) Å) (Fig. S5 and Table S3, ESI $\dagger$ ). Although the movement of the paddle-wheel SBUs does not drastically affect the overall 3D packing of the framework, the rotational rearrangement leads to positional changes of the individual atoms in 2-MeCN (Fig. 2b). The total solvent-accessible volume, as estimated using PLATON, ${ }^{15}$ shows that the calculated guest accessible area per unit cell volume for $2-\mathrm{MeCN}(64.2 \%)$ is similar to that of 1 . In relation to the mother framework $\mathbf{1}$, here also, highly disordered guest solvent molecules cannot be mapped using single crystal XRD. Bulk purity of 2-MeCN is corroborated by PXRD measurements, which reveal perfect agreement between the simulated pattern and also with the pattern obtained for $\mathbf{1}$ (Fig. S25, ESI $\dagger$ ). After careful screening

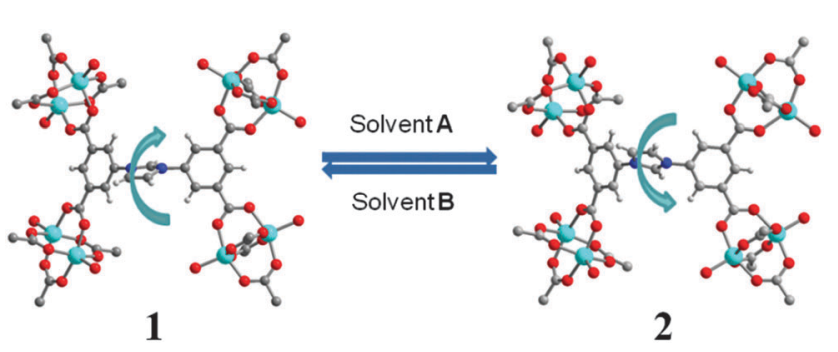

a)
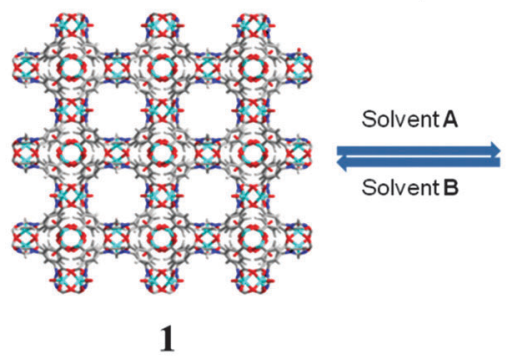

b)

Fig. 2 (a) Solvent induced reversible orientation of the imidazolium moiety and (b) parallel movement in the $\mathrm{Zn}_{2}\left(\mathrm{CO}_{2}\right)_{4}$ paddle-wheel unit, leading to a positional change in the packing diagram of $\mathbf{1}$ and $\mathbf{2}$ along the $C$-axis (solvent A: solvent molecules that do not have an oxygen atom as a part of their molecule; solvent B: solvent molecules having at least one oxygen atom as a part of their molecule). 
of different solvents (Table S4, ESI $\dagger$ ), we conclude that the above SC-SC structural deformation phenomena transpire in the presence of solvents (DCM, chloroform, carbon tetrachloride, acetonitrile, toluene, and benzene) that do not have any oxygen atom as a part of their molecule.

Besides, 2-MeCN undergoes reversible SC-SC transformation to 1 (Table S2, ESI $\dagger$ ) at room temperature, upon exposing the former to solvents that have at least one oxygen atom as a part of their molecule, like DMSO, DMF, DEF, DMA, THF, $\mathrm{Me}_{2} \mathrm{CO}_{3}$ and alcohol (methanol, ethanol, and propanol). It should be pointed here that independent solvothermal synthesis of 2 by mixing $\mathbf{H}_{4} \mathbf{L}^{+}$and $\mathrm{Zn}$ (II) in the solvents that do not have an oxygen atom as a part of their molecule proved unsuccessful, signifying that SC-SC transformation is the only route towards its formation. The aforementioned results strongly indicate that the rotational movement of the molecular components in the crystal actually depends on the nature of solvent molecules. We assume that $\mathrm{H}$-bonding interaction between the ligand moiety and the guest solvent molecule is crucial for such solvent induced reversible single-crystal to single-crystal transformation. Unfortunately, we could not model the guest solvent molecule to assess those particular interactions. In order to further check the influence of the oxygen atom containing solvent on the transformation of 1 to 2 , additional experiments with different solvent ratios were carried out. As summarized in Table S4 (ESI $\dagger$ ), we confirm that even a small amount of oxygen atom containing solvent is sufficient to inhibit the aforesaid transformation.

Direct synthesis of the copper analogue of $\mathbf{1}$ by replacing $\mathrm{Zn}\left(\mathrm{NO}_{3}\right)_{2} \cdot 6 \mathrm{H}_{2} \mathrm{O}$ with $\mathrm{Cu}\left(\mathrm{NO}_{3}\right)_{2} \cdot 3 \mathrm{H}_{2} \mathrm{O}$, as described above, was not successful. The presence of paddle-wheel SBUs and accessibility of polyhedral SBBs from the large channels prompted us to explore the possibility of metal ion exchange within the framework via the post-synthesis approach. In principle, metal centers, having similar preferred coordination geometries, will undergo metalexchange reactions more readily, since low energy is needed to overcome changes in coordination geometry. To test our above hypothesis, crystals of $\mathbf{1}$ were immersed in a DMF solution of $\mathrm{Cu}\left(\mathrm{NO}_{3}\right)_{2} \cdot 3 \mathrm{H}_{2} \mathrm{O}(0.04 \mathrm{M})$ at room temperature, whereupon no apparent colour change occurred even throughout a one month long period. In contrast, when crystals of $\mathbf{1}$ were dipped in an acetonitrile solution of $\mathrm{Cu}\left(\mathrm{NO}_{3}\right)_{2} \cdot 3 \mathrm{H}_{2} \mathrm{O}(0.04 \mathrm{M})$, the original colourless crystals gradually turned into green-blue in $12 \mathrm{~h}$ while maintaining their original shapes and sizes (Fig. S28 ESI $\dagger$ ). The metal replacement was confirmed by the EPR spectrum (Fig. S29, ESI $\dagger$ ) of green-blue crystals. We attempted to confirm the Cu-exchanged framework by single-crystal XRD analysis, which indicates (Table S1, ESI $\dagger$ ) that the completely exchanged product has a similar framework as 2 with the formula $\left\{\left[\mathrm{Cu}_{2}(\mathbf{L})\left(\mathrm{H}_{2} \mathrm{O}\right)_{2}\right] \cdot \mathrm{NO}_{3}\right.$. $\left.y \mathrm{H}_{2} \mathrm{O} \cdot z \mathrm{MeCN}\right\}_{n}\left(2_{\mathrm{Cu}}-\mathrm{MeCN}\right)$. Furthermore, X-ray fluorescence spectroscopy (XFS) studies demonstrate that no significant amount of $\mathrm{Zn}$ (II) ions is left in the framework $2_{\mathrm{Cu}}-\mathrm{MeCN}$. Since a transmetalation reaction principally demands cleavage and formation of coordinate bonds, the aforesaid observations led us to hypothesize that solvent induced ligand flipping and consequent SBU twisting in $\mathbf{1}$ perturb the coordination geometry at the $\mathrm{Zn}$ (II) center, which ultimately facilitates replacement by $\mathrm{Cu}(\mathrm{II})$ in a SC-SC fashion. The kinetics of the

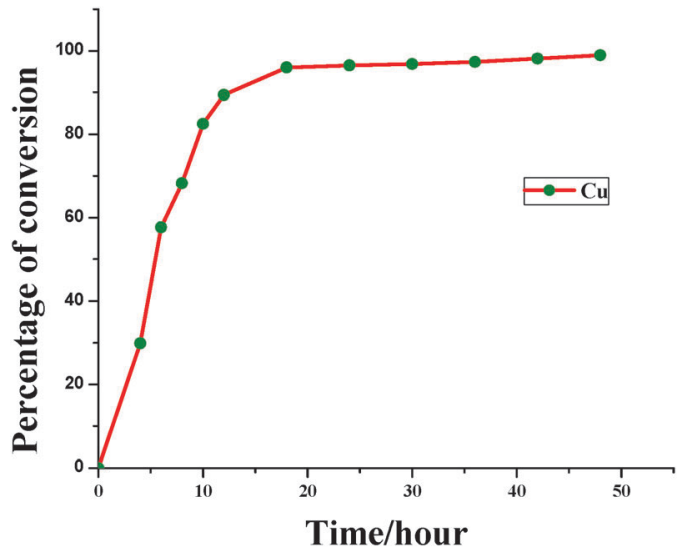

Fig. 3 Kinetic profile of the $\mathrm{Zn}(॥)$ to $\mathrm{Cu}(॥)$ transmetalation process.

$\mathrm{Zn}^{2+}$ to $\mathrm{Cu}^{2+}$ ion exchange process was monitored by energydispersive X-ray spectroscopy, which showed that nearly $50 \%$ of the framework $\mathrm{Zn}^{2+}$ ions were replaced by $\mathrm{Cu}^{2+}$ within $1 \mathrm{~h}$, and $95 \%$ of the $\mathrm{Zn}^{2+}$ ions were exchanged by $\mathrm{Cu}^{2+}$ within $12 \mathrm{~h}$ (Fig. 3 ). Complete exchange (99\%) is achieved in two days.

Having successfully converted framework $\mathbf{1}$ to $\mathbf{2}_{\mathbf{C u}}$, we finally examined whether we can generate the structure $\mathbf{1}_{\mathbf{C u}}$ through solvent induced reversible SC-SC structural transformation. As observed from single crystal X-ray diffraction studies (Table S1, $\mathrm{ESI} \dagger$ ), the blue crystals of $\mathbf{2}_{\mathbf{C u}}$-MeCN indeed change to $\mathbf{1}_{\mathbf{C u}}$-DMF, when kept in DMF for 2 days, as a consequence of the reorientation of the imidazolium moiety. During the transmetalation reaction, the average $\mathbf{M}-\mathbf{M}$ distance in the $\mathrm{M}_{2}\left(\mathrm{CO}_{2}\right)_{4}$-paddle-wheel units (Table S3, ESI $\dagger$ ) changes from $3.008 \AA$ ( $\mathrm{Zn}-\mathrm{Zn})$ in 1 to $2.658 \AA$ $(\mathrm{Cu}-\mathrm{Cu})$ in $2_{\mathrm{Cu}}-\mathrm{MeCN}$ (Fig. S6, ESI $\dagger$ ) that further changes to $2.679 \AA$ in $\mathbf{1}_{\mathbf{C u}}$-DMF (Fig. S7, ESI $\dagger$ ). The experimental PXRD patterns of $\mathbf{1}_{\mathbf{C u}}$-DMF and $\mathbf{2}_{\mathbf{C u}}-\mathrm{MeCN}$ (Fig. S26 and S27, ESI $\dagger$ ), respectively, are identical to their simulated patterns, signifying bulk purity. Moreover, the PXRD patterns of the transmetalated frameworks are similar to that of their corresponding mother Zn(II)-frameworks, demonstrating that the frameworks were preserved throughout the metal-ion exchange. In a similar way, 2 also undergoes structural transformation with concomitant transmetalation to $\mathbf{1}_{\mathbf{C u}}$ (Table S1, $\mathrm{ESI} \dagger)$ in a $\mathrm{Cu}\left(\mathrm{NO}_{3}\right)_{2}$ solution of a solvent that does not have any oxygen atom as a part of their molecule. It should be noted that the straightforward metal replacement, i.e. 2 to $2_{\mathrm{Cu}}$, does not occur, demonstrating once more (vide supra) that flipping of the imidazolium moiety with a parallel twist in $\mathrm{Zn}_{2}\left(\mathrm{CO}_{2}\right)_{4}$ SBUs is an essential prerequisite for the metal exchange to take place in these frameworks. However, the reverse transmetalation processes do not occur, i.e., for both $\mathbf{1}_{\mathrm{Cu}}$-DMF and $\mathbf{2}_{\mathrm{Cu}}$-MeCN, Cu(II) ions cannot be replaced by $\mathrm{Zn}$ (II) ions even in a concentrated DMF-MeCN solution of $\mathrm{Zn}\left(\mathrm{NO}_{3}\right)_{2} \cdot 6 \mathrm{H}_{2} \mathrm{O}(1 \mathrm{M})$ under long exchange time (1 month), suggesting that the $\mathrm{Cu}(\mathrm{II})$-frameworks are more stable than the corresponding $\mathrm{Zn}$ (II)-frameworks. ${ }^{13 c}$

In conclusion, using an angular tetracarboxylic acid ligand $\mathbf{H}_{4} \mathbf{L}^{+}$, incorporating an imidazolium group, we have synthesized a $3 \mathrm{D}$ cationic $\mathrm{Zn}$ (II) framework, based on $\mathrm{Zn}_{2}\left(\mathrm{CO}_{2}\right)_{4}$ paddle-wheel SBUs and $\mathrm{Zn}_{16}\left(\mathrm{CO}_{2}\right)_{32}$ polyhedral SBBs. At room temperature, the framework undergoes reversible SC-SC structural transformation 
as a consequence of the reorientation in the imidazolium moiety, in the presence of solvents that do not have any oxygen atom as a part of their molecule. Although the straightforward metal replacement, i.e. $\mathbf{1}$ to $\mathbf{1}_{\mathrm{Cu}}$, does not occur, framework $\mathbf{1}$ undergoes transformation with concomitant transmetalation to $\mathbf{2}_{\mathbf{C u}}$ in the presence of solvents that have no oxygen atom as a part of their molecule. Similarly, 2-MeCN undergoes metal exchange to $\mathbf{1}_{\mathbf{C u}}$ only when dipped in solvents that have at least one oxygen atom as a part of their molecule. The results demonstrate that flipping of the imidazolium moiety with a parallel twist in $\mathrm{Zn}_{2}\left(\mathrm{CO}_{2}\right)_{4} \mathrm{SBUs}$ is an essential prerequisite for the metal exchange to take place in these frameworks. To the best of our knowledge, this is the first report exemplifying SC-SC transmetalation as a consequence of the change in ligand conformation and should provide insight in fabricating switch emergent molecular devices. The possibility of transmetalation reactions and their kinetics with different transition metal ions are currently underway.

We gratefully acknowledge the financial support from the Department of Science and Technology, New Delhi, India (J.C. Bose National Fellowship to P.K.B.). S.N. thanks IIT Kanpur for a postdoctoral fellowship. Dr Fangfang Pan (Chem Dept, Jyväskylä) is thanked for some preliminary structural work on $\mathbf{1}$ and 2-MeCN. The Academy of Finland (KR grant no. 265328 and 263256) is kindly acknowledged for financial support.

\section{Notes and references}

1 (a) T. A. Makal, J.-R. Li, W. Lu and H.-C. Zhou, Chem. Soc. Rev., 2012, 41, 7761-7779; (b) B. Li, H.-M. Wen, W. Zhou and B. Chen, J. Phys. Chem. Lett., 2014, 5, 3468-3479.

2 D. J. Tranchemontagne, J. L. Mendoza-Cortés, M. O'Keeffe and O. M. Yaghi, Chem. Soc. Rev., 2009, 38, 1257-1283.

3 (a) T. H. Park, A. J. Hickman, K. Koh, S. Martin, A. G. Wong-Foy, M. S. San-ford and A. J. Matzger, J. Am. Chem. Soc., 2011, 133, 20138-20141; (b) S. Horike, M. Dincă, K. Tamaki and J. R. Long, J. Am. Chem. Soc., 2008, 130, 5854-5855; (c) K. S. Jeong, Y. B. Go, S. M. Shin, S. J. Lee, J. Kim, O. M. Yaghi and N. Jeong, Chem. Sci., 2011, 2, 877-882; (d) F. Vermoortele, M. Van-dichel, B. V. Voorde, R. Ameloot, M. Waroquier, V. V. Speybroeck and D. E. D. Vos, Angew. Chem., Int. Ed., 2012, 51, 4887-4890.
4 G. J. T. Cooper, G. N. Newton, P. Kçgerler, D. L. Long, L. Engelhardt, M. Luban and L. Gronin, Angew. Chem., 2007, 119, 1362-1366 (Angew. Chem., Int. Ed., 2007, 46, 1340-1344).

5 S. R. Caskey and A. J. Matzger, Inorg. Chem., 2008, 47, 7942-7944.

6 (a) S. Neogi, S. Sen and P. K. Bharadwaj, CrystEngComm, 2013, 15, 9239-9248; (b) Y. Han, J.-R. Li, Y. Xie and G. Guo, Chem. Soc. Rev., 2014, 43, 5952-5981; (c) H. Aggarwal, P. Lama and L. J. Barbour, Chem. Commun., 2014, 50, 14543-14546; (d) M. C. Das and P. K. Bharadwaj, J. Am. Chem. Soc., 2009, 131, 10942-10949; (e) M. C. Das and P. K. Bharadwaj, Chem. - Eur. J., 2010, 16, 5070-5077; $(f)$ R. K. Das, A. Aijaz, M. K. Sharma, P. Lama and P. K. Bharadwaj, Chem. - Eur. J., 2012, 18, 6866-6872.

7 (a) E. Y. Lee, S. Y. Jang and M. P. Suh, J. Am. Chem. Soc., 2005, 127, 6374-6381; (b) M. K. Sharma and P. K. Bharadwaj, Inorg. Chem., 2011, 50, 1889-1897; (c) H. Aggarwal, P. M. Bhatt, C. X. Bezuidenhout and L. J. Barbour, J. Am. Chem. Soc., 2014, 136, 3776-3779.

8 (a) C. K. Brozek and M. Dincă, Chem. Sci., 2012, 3, 2110-2113; (b) Z. Zhang, L. Wojtas, M. Eddaoudi and M. J. Zaworotko, J. Am. Chem. Soc., 2013, 135, 5982-5985; (c) J.-R. Li and H.-C. Zhou, Nat. Chem., 2010, 2, 893-898; (d) T. Li, M. T. Kozlowski, E. A. Doud, M. N. Blakely and N. L. Rosi, J. Am. Chem. Soc., 2013, 135, 11688-11691.

9 G. J. Halder and C. J. Keppert, J. Am. Chem. Soc., 2005, 127, 7891-7900. 10 (a) C. G. Bezzu, M. Helliwell, J. E. Warren, D. R. Allan and N. B. McKeown, Science, 2010, 327, 1627-1630; (b) H. J. Park, Y. E. Cheon and M. P. Suh, Chem. - Eur. J., 2010, 16, 11662-11669; (c) B. J. Burnett, P. M. Barron, C. Hu and W. Choe, J. Am. Chem. Soc., 2011, 133, 9984-9987; (d) T. Li, M. T. Kozlowski, E. A. Doud, M. N. Blakely and N. L. Rosi, J. Am. Chem. Soc., 2013, 135, 11688-11691.

11 (a) S. Das, H. Kim and K. Kim, J. Am. Chem. Soc., 2009, 131, 3814-3815; (b) J. Tian, L. V. Saraf, B. Schwenzer, S. M. Taylor, E. K. Brechin, J. Liu, S. J. Dalgarno and P. K. Thallapally, J. Am. Chem. Soc., 2012, 134, 9581-9584; (c) T.-F. Liu, L. Zou, D. Feng, Y.-P. Chen, S. Fordham, X. Wang, Y. Liu and H.-C. Zhou, J. Am. Chem. Soc., 2014, 136, 7813-7816.

12 (a) S. Huang, X. Li, X. Shi, H. Hou and Y. Fan, J. Mater. Chem., 2010, 20, 5695-5699; (b) Y. Han, N. F. Chilton, M. Li, C. Huang, H. Xu, H. Hou, B. Moubaraki, S. K. Langley, S. R. Batten, Y. Fan and K. S. Murray, Chem. - Eur. J., 2013, 19, 6321-6328.

13 (a) D. Denysenko, T. Werner, M. Grzywa, A. Puls, V. Hagen, G. Eickerling, J. Jelic, K. Reuter and D. Volkmer, Chem. Commun., 2012, 48, 1236-1238; (b) X. J. Wang, P. Z. Li, L. Liu, Q. Zhang, P. Borah, J. D. Wong, X. X. Chan, G. Rakesh, Y. Li and Y. Zhao, Chem. Commun., 2012, 48, 10286-10288; (c) X. Song, T. K. Kim, H. Kim, D. Kim, S. Jeong, H. R. Moon and M. S. Lah, Chem. Mater., 2012, 24, 3065-3073.

14 S. Sen, S. Neogi, A. Aijaz, Q. Xu and P. K. Bharadwaj, Inorg. Chem., 2014, 53, 7591-7598.

15 A. L. Spek, J. Appl. Crystallogr., 2003, 36, 7-13. 